\section{La recepción de Homero en Alejandría: la edición homérica de Aristarco}

Recibido: 19/06/2018. Aceptado: 18/12/2018

\title{
Resumen
}

El artículo discute la recepción de Homero en la Alejandría helenística, particularmente en la obra de Aristarco de Samotracia. Después de analizar brevemente cómo la edición de Aristarco tuvo un impacto en el texto homérico que todavía leemos en la actualidad, el artículo se enfoca en el método y los principios seguidos por Aristarco en su trabajo sobre la Ilíada. A través del análisis de algunos ejemplos específicos, muestra cómo las propias ideas de Aristarco sobre Homero tuvieron un efecto en el texto homérico que produjo, lo que plantea la cuestión de la recepción de un autor literario por los filólogos y los problemas relacionados con ella.

\section{The reception of Homer in Alexandria: the Homeric edition of Aristarchus}

\begin{abstract}
The article discusses the reception of Homer in Hellenistic Alexandria, particularly in the work of Aristarchus of Samothrace. After briefly analyzing the impact of Aristarchus' edition on the Homeric text that we still read today, it focuses on the method and principles followed by Aristarchus in his work on the Iliad. Through the analysis of some specific examples, it shows how Aristarchus' own ideas about Homer greatly shaped the Homeric text that he produced; it thus raises the question of the reception of a literary author by philologists and the problems related to it.
\end{abstract}

\section{Palabras clave}

Aristarco de Samotracia ediciones antiguas de Homero filología helenistica Biblioteca de Alejandría Venetus $A$

\section{Keywords}

Aristarchus of Samothrace Ancient editions of Homer Hellenistic philology Library of Alexandria Venetus $A$ 
1. Este texto es el resultado de una charla que presenté en el Instituto de Filología Clásica de la UBA en abril de 2018 y que recoge parte del resultado de mi monografía sobre Aristarco (Schironi, 2018). Me gustaría agradecer a los colegas y estudiantes presentes en mi conferencia por sus observaciones, preguntas y comentarios muy útiles.

2. Sobre Alejandría, la Biblioteca y el Museo, cfr. Pfeiffer (1968: 98-104); Fraser (1972: I 305-335); Bagnall (2002), la mejor discusión sobre la Biblioteca, en mi opinión.

3. Sobre la filología Alexandria en general, cfr. Fraser (1972:l 447-479) y Pfeiffer (1968: 87-233).
El texto homérico experimentó un desarrollo fundamental en Alejandría cuando fue editado y comentado por los gramáticos que trabajaban en la Biblioteca Real, particularmente por Aristarco de Samotracia (216-144 a.C.), el último y más importante estudioso de la Alejandría helenística. En este artículo daré una visión general de cómo el texto homérico se 'recibió' en Alejandría. Después de una introducción sobre el trabajo llevado a cabo en la Biblioteca de Alejandría, me concentraré en el trabajo de Aristarco sobre Homero: sobre las fuentes que conservan los fragmentos de Aristarco, cómo eran sus ediciones y comentarios y cuál fue el impacto de su edición en la vulgata moderna. En la segunda parte, me enfocaré en el trabajo exegético de Aristarco sobre Homero: sus características, rasgos innovadores y algunos de los problemas que conlleva. ${ }^{1}$

Alejandría es famosa por el Museo y la Biblioteca que fueron fundados por los primeros dos Ptolomeos, Ptolomeo Soter (306-282 a.C.) y Ptolomeo Filadelfo (282-246 a.C.). Los reyes contrataron a eruditos elegidos de acuerdo con sus méritos intelectuales para trabajar en la biblioteca, preparar ediciones y comentarios y también enseñar a los niños de la realeza. ${ }^{2}$ Como es sabido, no solo había gramáticos 'puros' activos en Alejandría; también hubo poetas famosos, como Calímaco y Apolonio de Rodas que fueron empleados en la biblioteca como filólogos.

El principal logro de los eruditos alejandrinos de este período es la reorganización de la antigua tradición literaria de Grecia y la producción de ediciones estándar ( $\dot{\kappa} \kappa \delta o ́ \sigma \varepsilon ı \varsigma)$ de los autores griegos, que son la base de la tradición medieval que todavía utilizamos. El trabajo sobre la literatura arcaica y clásica llevado a cabo en Alejandría condujo también a la formación del 'canon': estos filólogos seleccionaron a los autores más representativos para cada género y es su selección la que ha dado forma a nuestra tradición clásica. ${ }^{3}$

Sin embargo, todo esto fue posible gracias al mecenazgo real. De hecho, no solo se trataba de pagar a los gramáticos y bibliotecarios para que estudiaran estos textos, sino también (lo que es más importante) de darles la oportunidad y los medios para hacer su trabajo, que para los filólogos y eruditos son obviamente los libros. Los Ptolomeos adquirieron libros de todo el mundo griego. Galeno describe cómo se adquirieron los rollos para la Biblioteca (Comm. Hipp. Epidem. iii, 6o6-6o7 = CMG V, 10.2.1, 79.7-80.6): Ptolomeo III (246-222 a.C.) había emitido una orden para que todos los libros sobre barcos que llegaran a Alejandría fueran requisados y copiados: los originales se guardaban en la Biblioteca, mientras que a los propietarios solo se les devolverían las copias. Lo mismo sucedió con la edición ateniense de los tres trágicos: Ptolomeo III la había tomado prestada de los atenienses dando una garantía de quince talentos, con el acuerdo de que la copiaría y devolvería los rollos originales de inmediato. Pero el rey se quedó con los originales y envió copias a Atenas. Estas anécdotas sugieren que el objetivo de los Ptolomeos era recoger todos los libros posibles que llegaran a Alejandría, así como manuscritos antiguos y originales, no simplemente copias; de hecho, Galeno comenta que la historia de la edición ateniense de los tres trágicos demuestra que Ptolomeo III estaba extremadamente interesado en adquirir todos los libros antiguos (CMG V,

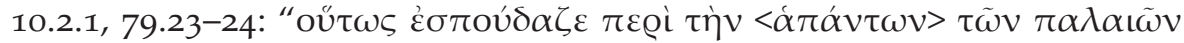

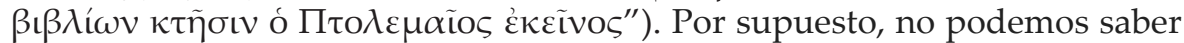
hasta qué punto estas anécdotas son confiables, pero su testimonio encuentra confirmación en los escolios homéricos de Dídimo, que mencionan la presencia en la Biblioteca de muchas ediciones homéricas, al menos entre el siglo I a.C. y principios del siglo I d.C., cuando él estaba trabajando allí. Se mencionan 
dos tipos diferentes de ediciones. El primer grupo consiste en ediciones individuales ( $\dot{\kappa} \kappa \delta o ́ \sigma \varepsilon ı \varsigma \kappa \alpha \tau^{\prime} \not \partial v \delta \varrho \alpha$ ), es decir, ediciones preparadas por académicos específicos. Además de las ediciones de Zenódoto, Aristófanes y Aristarco (quienes fueron todos bibliotecarios principales en Alejandría), Dídimo también recuerda a las de Riano de Creta, Antímaco, Sosígenes, Calístrato y

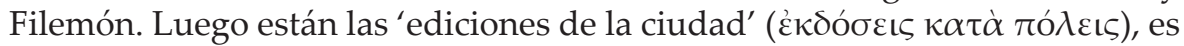
decir, ediciones preparadas por ciudades específicas o, mejor dicho, copias procedentes de dichas ciudades. Entre las últimas, los escolios registran las ediciones de Marsella, Quío, Argos, Chipre, Sinope, Creta y una edición ‘eóli$\mathrm{ca}^{\prime}{ }^{4}$ Esta lista en particular da una idea de la extensión geográfica de la caza de libros por los Ptolomeos en las partes más remotas del mundo griego, desde Marsella a Sinope en el Mar Negro. Entonces, en la época de los Ptolomeos la colección era enorme, aunque también es verdad que el número dado por Tzetzes (Prol. XIa II, 6-11 Koster), es decir, 490.000 libros (i.e., rollos) en la Biblioteca es probablemente exagerado.

El número y orden de los bibliotecarios principales en Alejandría han sido muy debatidos. Las principales fuentes son P.Oxy. 1241 (siglo II d.C.), las entradas de Suda (siglo X) sobre las vidas de estos eruditos (en su mayoría derivados de los Onomatologos por Hesiquio de Mileto), y Prolegómenos de Juan Tzetzes a sus comentarios a Aristófanes; pero esta es la lista estándar: ${ }^{5}$

\begin{tabular}{|c|c|}
\hline Bibliotecario & Rey \\
\hline Zenódoto de Éfeso (ca. 285-270 a.C.) & $\begin{array}{l}\text { Ptolomeo I Soter (306-282 a.C.) } \\
\text { Ptolomeo II Filadelfo (282-246 a.C.) }\end{array}$ \\
\hline Apolonio de Rodas (ca. 270-245 a.C) & Ptolomeo II Filadelfo (282-246 a.C.) \\
\hline $\begin{array}{l}\text { Eratóstenes de Cirene (ca. 245-204/201 } \\
\text { a.C) }\end{array}$ & $\begin{array}{l}\text { Ptolomeo III Evergetes I (246-222 a.C.) } \\
\text { Ptolomeo IV Filopator (222-204 a.C.) } \\
\text { Ptolomeo V Epífanes (204-180 a.C.) }\end{array}$ \\
\hline $\begin{array}{l}\text { Aristófanes de Bizancio (ca. 204/201- } \\
\text { 189/186 a.C) }\end{array}$ & Ptolomeo V Epífanes (204-180 a.C.) \\
\hline $\begin{array}{l}\text { Apolonio Eidógrafo (ca. 189/186-175 } \\
\text { a.C) }\end{array}$ & $\begin{array}{l}\text { Ptolomeo V Epífanes (204-180 a.C.) } \\
\text { Ptolomeo VI Filometor (180-145 a.C.) }\end{array}$ \\
\hline $\begin{array}{l}\text { Aristarco de Samotracia (ca. 175-145 } \\
\text { a.C.) }\end{array}$ & Ptolomeo VI Filometor (180-145 a.C.) \\
\hline
\end{tabular}

Aristarco fue el último de los bibliotecarios en esta lista y, sin embargo, la cima de la erudición en Alejandría. Después de él, el apogeo ha terminado, aunque es verdad que la actividad de eruditos como Dídimo, Trifón y Theón - todos los cuales trabajaron en Alejandría entre el primer siglo a.C. y el primer siglo d.C. - demuestra que el trabajo académico nunca cesó realmente en la Biblioteca.

Entre los siglos tercero y segundo a.C. en Alejandría había muchos científicos, como los médicos Praxágoras y Erófilo, quien avanzó en el conocimiento anatómico del cuerpo humano. También los matemáticos Conón de Samos, Eratóstenes y Apolonio de Perge trabajaron allí en este período. Eratóstenes, el tercer bibliotecario y el tutor de Ptolomeo IV, es una figura muy interesante. Era científico, matemático, geógrafo y filólogo; escribió sobre comedia y sobre la lengua griega, pero también calculó la circunferencia de la tierra con una muy buena aproximación. En cierto sentido, entonces, Eratóstenes representa
4. Cfr. West (2001:50-73).

$$
\begin{aligned}
& \text { 5. Cfr. Fraser (1972: I 330-333). } \\
& \text { Tanto el orden como las fechas de } \\
& \text { cada bibliotecario están sujetas } \\
& \text { a debate; para una ordenación } \\
& \text { ligeramente diferente (en mi opinión, } \\
& \text { más correcta), en la que Apolonio } \\
& \text { Eidógrafo precedió a Aristófanes de } \\
& \text { Bizancio, cfr. Eichgrün (1961:15-35). }
\end{aligned}
$$


6. Sobre la ciencia en Alejandría, cfr. Fraser (1972:I 336-446); Russo (2004); Schironi (2019).

7. Tzetzes, Prol. XIa I, 11-12 Koster:

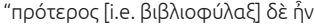

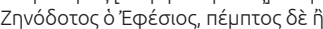

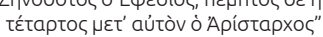
[el primer bibliotecario fue Zenodoto de Éfeso, el quinto o el cuarto después de él fue Aristarco].

8. Sobre la tradición aristarquea, el VMK y los escolios homéricos (especialmente el Venetus A), cfr. Lehrs (1882:1-35), un poco desactualizado pero aún útil; Erbse (1969:xlv-lix); Pontani (2005:96-100, 148-156, 170-182), con más bibliografía. Podemos suponer con más bibliografía. Podemos suponer la Odisea, ya que tenemos escolios sobre esta obra que derivan de las mismas cuatro autoridades. Aun así, no tenemos nada como el Venetus $A$ para la Odisea. Cfr. Pontani (2005:148-150). bien el sincretismo científico y académico típico de la Alejandría helenística, uno de los lugares más brillantes intelectualmente del Mediterráneo y a la vanguardia de la investigación en muchos campos. ${ }^{6}$

Aristarco es parte de este entorno innovador. Y en este artículo intentaré mostrar cómo Aristarco puede ser considerado el fundador de la filología moderna y casi el creador de una 'metodología científica' para el tratamiento de cuestiones textuales y exegéticas. Su método innovador se mostrará evidente cuando comparemos su actitud hacia Homero con la de su famoso predecesor como editor de Homero, Zenódoto. Este último, que fue el primer bibliotecario de Alejandría, ${ }^{7}$ es objeto de las críticas de Aristarco como representante de un tipo de filología metodológicamente defectuosa, a la que Aristarco opone su análisis 'científicamente fundamentado'.

\section{La 'tradición aristarquea'}

Uno de los principales problemas en el estudio de Aristarco es tratar con las fuentes donde se conservan sus fragmentos, ya que ninguna de sus obras nos ha llegado por tradición directa. Esto se debe en parte al hecho de que las ediciones y comentarios de Aristarco no estaban destinados a un público amplio; no eran textos para el mercado, sino que solo fueron utilizados en la Biblioteca por otros eruditos; por lo tanto, su circulación fue limitada.

Aunque sus obras originales se perdieron, muchos fragmentos aún se pueden recuperar gracias a la literatura gramatical y exegética posterior. Ello es posible porque los textos eruditos antiguos se caracterizan por una reutilización continua del mismo material, que se cita, se vuelve a copiar y se resume a través de los siglos. Por esta razón, ahora podemos encontrar muchos fragmentos de Aristarco en obras que datan del período bizantino, tales como los escolios a Homero, el comentario homérico de Eustacio de Tesalónica y los léxicos etimológicos bizantinos. Podemos llamar a esta la 'tradición aristarquea', de la que se reproduce el stemma a continuación: ${ }^{8}$

Sigla (las fuentes que todavía están disponibles para nosotros están en negrita):

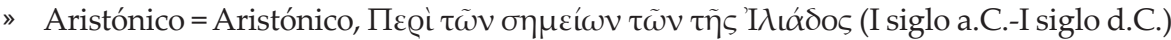

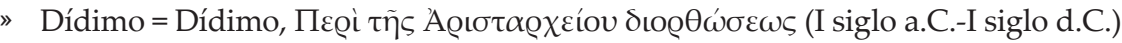

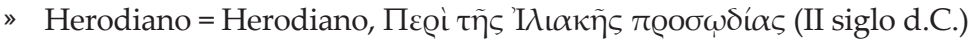

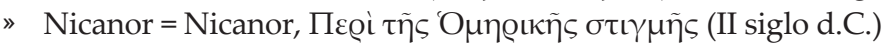

» $\mathrm{VMK}=$ Viermännerkommentar (siglo V-VI d.C.)

» $\mathrm{a}=$ códice bizantino derivado del VMK y utilizado por ApH (cfr. Erbse, 1969:liii)

" $\mathrm{C}=$ arquetipo perdido de las dos principales colecciones de escolios exegéticos ( $\mathrm{T}$ y b)

» 'Comm. Ex.' = colecciones anónimas y perdidas de escolios exegéticos

" Porph. QH = Porfirio, Questiones Homericas (siglo III)

»Sch. D = Scholia Didymi o escolios D

"Ap. H. = comentario de Apione y Erodoro

》Sch. A = escolios en el Codex Venetus A (Marc. Gr. 454, siglo X)

"Sch. $\mathrm{A}^{\mathrm{a}}=$ escolios en el Codex Athous Gr. Vatopedi 595 (siglo XV)

»Sch. $\mathbf{b}=$ escolios en la familia $\mathbf{b}$ de códices a la Ilíada (mss. $\left.\mathrm{BCE}^{3} \mathrm{E}^{4}\right)$

"Sch. T = escolios en el Codex Townleianus (Brit. Mus. Burney 86, 1014 o 1059)

»Sch. Ge = escolios en el Codex Genavensis Gr. 44 (siglo XIII)

" EGen. = Etymologicum Genuinum (siglo IX)

» EGud. = Etymologicum Gudianum (siglo XI-XII) 
"ESym. = Etymologicum Symeonis (siglo XII)

» EM= Etymologicum Magnum (siglo XII)

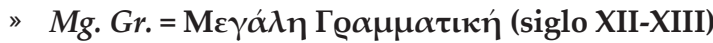

"Zon. = Zonarae Lexicon (siglo XII-XIII)

» Eust. = Eustathii archiepiscopi Thessalonicensis Commentarii ad Homerum (siglo XII)

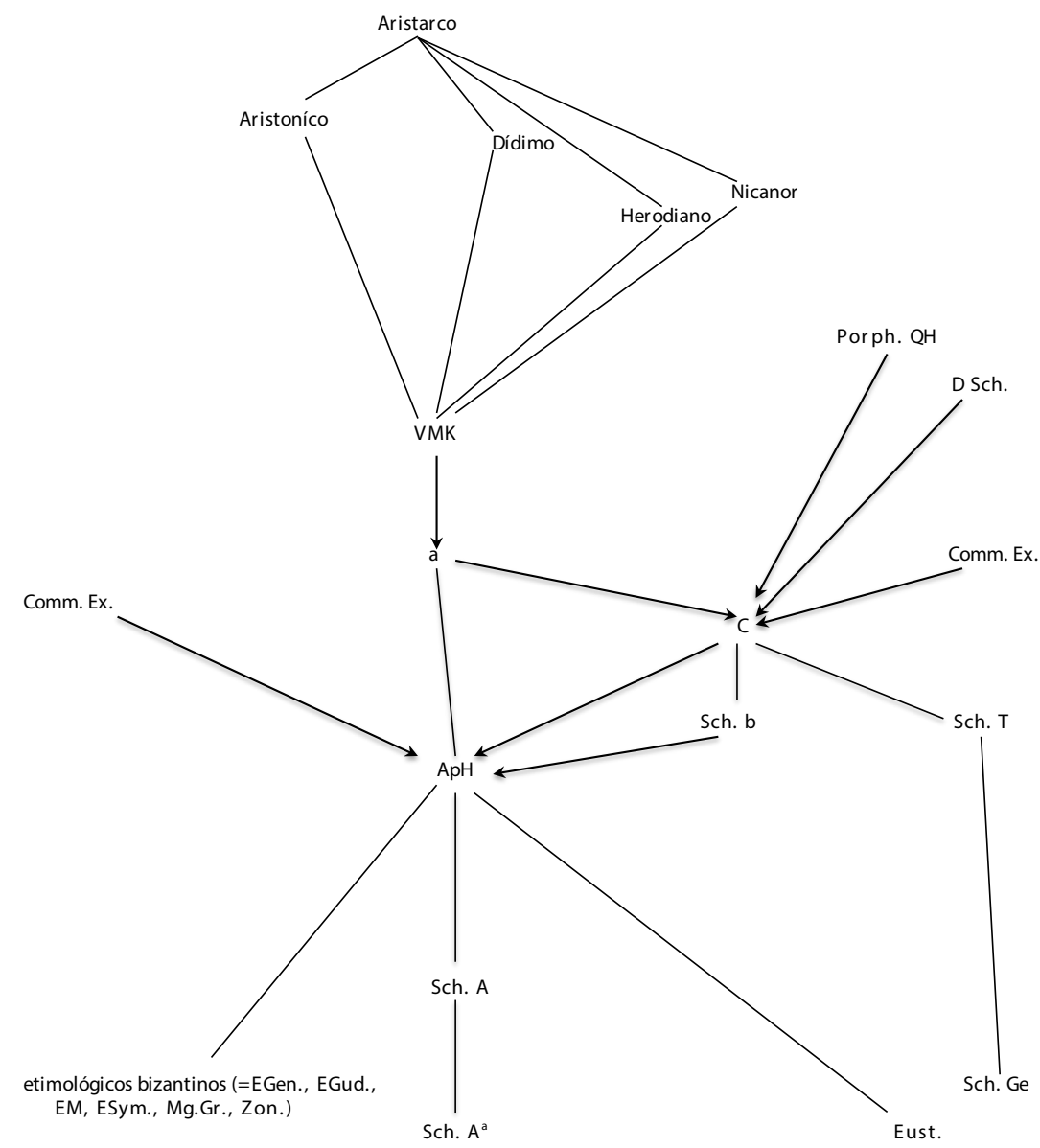

La tarea de 'salvar' a Aristarco fue emprendida especialmente por dos eruditos de la escuela aristarquea entre los siglos primero a.C. y primero d.C.: Aristónico y Dídimo. Aristónico escribió un tratado para explicar el significado de los

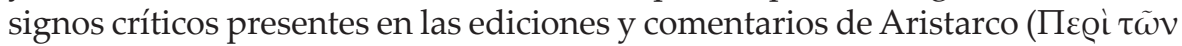

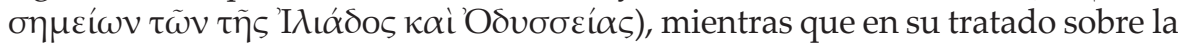

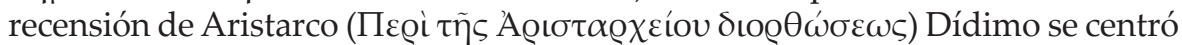
en las lecturas elegidas por Aristarco en su recensión homérica. Más tarde, en el siglo II d.C., otros dos eruditos, Herodiano y Nicanor, escribieron sobre Aristarco; el primero analizó las cuestiones de prosodia y acentuación en el len-

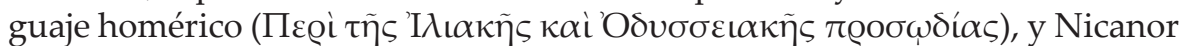

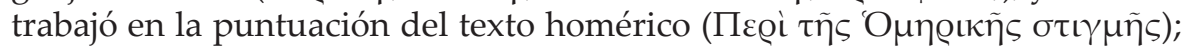
en estos tratados ambos tomaron en consideración lo que dijo Aristarco sobre estos temas. Una vez más, ninguna de estas obras ha sido preservada por tradición directa; sin embargo, en los siglos V y VI se recopilaron juntas en el llamado Viermännerkommentar, el 'comentario de los cuatro hombres', es decir, Aristónico, Dídimo, Nicanor y Herodiano. Este trabajo tampoco sobrevivió, pero fue la base de las sucesivas obras de erudición en la antigüedad tardía, algunas de las cuales se han conservado, como se describe en el stemma. 
9. Sobre lecturas alegóricas y simbolismo en la antigüedad, cfr. Wehrli (1928); Buffière (1956); Long (1992), estoicismo y alegoría; Lamberton (1992), neoplatonismo y alegoría; BoysStones (2003: Parte II); Struck (2004).
En particular, el códex Venetus A de la Ilíada del siglo X es muy importante para el estudio de Aristarco porque en sus márgenes conserva los signos críticos utilizados por él y un inmenso número de escolios, es decir, anotaciones marginales e interlineales, muchos de los cuales nos remiten a Aristarco. Además, el Venetus A tiene una suscripción al final de cada canto que dice que los escolios derivan de las obras de los 'cuatro hombres':

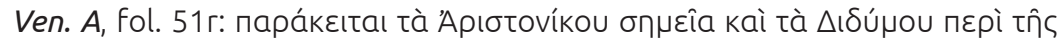

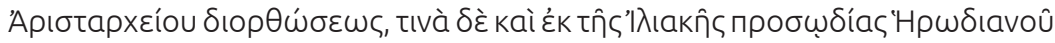

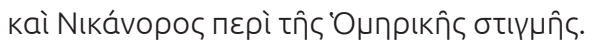

El [tratado titulado] Signos Críticos por Aristónico y el [tratado] Sobre la Recensión de Aristarco por Dídimo se agregan aquí; también hay algunos [extractos] del [tratado titulado] Acentuación lliádica por Herodiano y de la Puntuación de Homero por Nicanor.

La nota muestra que la mayor parte de los escolios en el Venetus A deriva de Aristónico y Dídimo, con algunas adiciones de los últimos tratados de Herodiano y Nicanor. Estos escolios en el Venetus $A$, en particular los de Aristónico, son una base fundamental de cualquier estudio sobre Aristarco.

\section{Los problemas principales en Homero.}

Los antiguos eruditos (y lectores) se enfrentaron a tres problemas principales al leer a Homero. El primer problema es muy conocido: todos saben que los dioses homéricos no son los dioses que nos gustaría tener: son egoístas, no les importan los humanos ni la moral en general. Este problema surgió muy pronto: cuando la filosofía comenzó a desarrollarse, filósofos como Jenófanes de Colofón (ca. 570-467 a.C.) comenzaron a criticar a esos dioses. La respuesta de los eruditos fue proponer lecturas alegóricas: de acuerdo con tal planteamiento los dioses no son realmente dioses, sino símbolos de los fenómenos naturales-por ejemplo, Apolo es el sol, Zeus es el cielo. Por lo tanto, en realidad no se trataría de dioses, y como consecuencia ya no había ningún problema religioso. ${ }^{9}$ Aristarco, por su lado, no se molesta con este problema. Para él, los dioses son como los otros personajes, Aquiles o Agamenón-por esta razón, no tiene problema alguno en que los dioses homéricos se comporten tan mal como los humanos. Por supuesto, tampoco le gusta usar lecturas alegóricas para salvar la decencia divina. Su opinión se conserva en un famoso escolio:

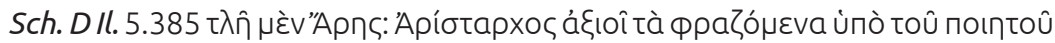

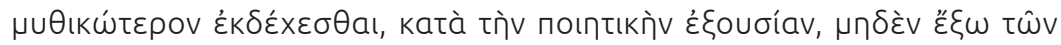

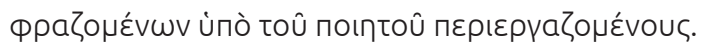

'Así sufrió Ares': Aristarco piensa que lo que dice el poeta se debe entender como una ficción, según la licencia poética, sin sobreinterpretar más allá de lo que ha dicho el poeta.

Esta es una visión muy interesante y moderna: la poesía es ficción y la base de todo es el texto. Aparte del rechazo de la alegoría, que no voy a discutir aquí, la idea sugerida en esta nota es que la única evidencia para un filólogo es el texto. Este principio es fundamental para Aristarco y será 
también el punto inicial de nuestro análisis. Esta nota entonces es importante porque dice mucho acerca de la actitud de Aristarco hacia Homero y hacia su trabajo de filólogo.

Otro problema muy importante para los eruditos antiguos fue la comprensión básica del texto, especialmente porque el texto homérico era un texto escolar con el que los niños solían aprender a escribir y leer. Pero el lenguaje homérico es un lenguaje literario, nunca hablado, y con una mezcla de diferentes dialectos y diferentes estratos cronológicos. Por eso los lectores clásicos y helenísticos tuvieron muchos problemas con el significado de ciertas palabras o frases homéricas y los filólogos se esforzaron mucho para aclarar el texto. Por esta razón, el análisis y la clarificación del lenguaje homérico, a pesar de ser una pregunta bastante simple, era central en el trabajo de Aristarco. ${ }^{10}$

El último problema fue solo para los profesionales que querían preparar una edición de Homero: el texto de los poemas homéricos no era fijo, sino multiforme. Este problema surgió porque la poesía homérica es poesía oral. Esto significa que no fue compuesta por escrito, sino en cada recitación oral, cuando el rapsoda componía su canción, improvisando en cada nueva actuación. Una y otra vez, los poetas o bardos orales recomponían sus poemas sobre la base del material tradicional. De hecho, incluso cuando tenían una forma escrita más o menos estable (ya Hiparco de Atenas estandarizó hasta cierto punto el texto de Homero para las recitaciones Panateneas), los poemas homéricos todavía se interpretaban oralmente. El resultado fue que estaban particularmente abiertos a interpolaciones, pues las performances orales dieron a los rapsodas un cierto grado de libertad para insertar $u$ omitir versos de fórmulas o escenas enteras. Esto condujo a la proliferación de diferentes textos de los poemas homéricos que, aunque básicamente idénticos en términos de trama y estructura, tenían un número diferente de versos. ${ }^{11}$ Tenemos evidencia de interpolaciones antiguas cuando comparamos 'nuestro Homero', es decir, aquel que es conservado por nuestros manuscritos medievales y que es más o menos homogéneo, sin muchas variantes (la vulgata), con otras fuentes antiguas, por ejemplo, citas de Homero en autores clásicos. Cuando Platón o los oradores citan versos de Homero, su texto es a veces diferente del nuestro, a pesar de que estas variaciones se refieren a menudo a lecturas únicas y no hacen que el texto de los poemas sea esencialmente diferente al nuestro en su estructura general. ${ }^{12}$ Aún más contundentes en este aspecto son los papiros más antiguos de Homero, aquellos que datan del período ptolemaico, desde el siglo III a.C. hasta la mitad del siglo II a.C. Estos papiros, que son alrededor de cuarenta y han sido estudiados por Stephanie West (1967), se han definido como papiros 'salvajes' ya que el texto homérico que conservan es diferente de 'nuestro' Homero, y está lleno de nuevos versos y lecturas diferentes, que se infiltraron en la tradición debido a las recitaciones orales. Lo que es muy interesante es que después de alrededor del 150 a.C. el texto homérico de los papiros no muestra versos adicionales y tiene básicamente el mismo número de versos que nuestra vulgata. Este cambio significativo se ha atribuido a la actividad editorial de Aristarco que, en su esfuerzo por producir un texto correcto de Homero sobre la base de muchas ediciones diferentes disponibles en Alejandría, eliminó versos que no estaban muy atestiguados en sus manuscritos y probablemente fueran adiciones posteriores. ${ }^{13}$ Por supuesto, está claro que Aristarco no tenía idea alguna de que la poesía homérica fuera poesía oral: para él, los poemas homéricos eran poesía 'escrita', y las tareas del filólogo consistían en recuperar su texto original como fue escrito por Homero.
10. Cfr. Schironi (2018:124-264).

11. Sobre las recitaciones orales de los poemas homéricos y su transmisión pre-alejandrina, véanse las diferentes teorías propuestas por Janko (1994:29-38); Nagy (1996:107-206) y West (2001:3-32).

12. Cfr. Labarbe (1949:esp. 409425); Nagy (2009:444-447).
13. Cfr. Collart (1933:53-54); West (1967:16-17); Bolling (1944:22-23); Erbse (1959:301-303); Pasquali (1962:216-217); Apthorp (1980:9-10); Janko (1994:22); Haslam (1997:8487); Schironi (2018:41-43). 
4. Cfr. Haslam (1997:84-87); Lührs (1992:9-10); Schironi (2018:43).

15. Cfr. Erbse (1959:301-302); van Groningen (1963:36-37); Jensen (1980:109-110).

\section{Las ediciones y comentarios de Aristarco sobre Homero}

¿Qué es entonces una edición antigua? Pues bien, es una cosa bastante diferente de una edición moderna donde un editor presenta el texto final y autorizado de un autor específico. Hoy en día creemos ${ }^{14}$ que un antiguo editor homérico elegiría un texto homérico específico que él considerara particularmente bueno. Aristarco probablemente inspeccionó muchos manuscritos homéricos diferentes recogidos en la Biblioteca. No sabemos qué texto eligió como copia base, pero se ha sugerido que Aristarco eligió la copia ateniense de Homero como su texto de trabajo. ${ }^{15}$ Independientemente de si este texto 'seleccionado' era la copia ateniense, Aristarco probablemente lo contrastó con otras ediciones en la Biblioteca y eliminó los versos mal atestiguados en otros manuscritos, de modo que su texto de trabajo fue una copia homérica seleccionada, purgada de versos no bien atestiguados. Probablemente, por lo tanto, Aristarco seleccionó la vulgata antigua, es decir, el texto homérico más común del periodo helenístico.

Sin embargo, este texto de Homero no era la edición 'real' de Aristarco, sino simplemente un texto preparatorio purgado de los versos seguramente espurios. Este 'texto preparatorio' elaborado por Aristarco circuló fuera del Museo y entró en el comercio del libro, por lo que el número de versos de la Ilíada y la Odisea establecido por él finalmente se convirtió en el estándar en el mundo griego y ha pasado a nuestra vulgata.

Por otra parte, la edición 'real' y 'científica' (ekdosis) era el mismo texto preparatorio, pero con agregados de signos críticos, variantes, sus propias correcciones y tal vez comentarios breves en el margen hechos por el filólogo. Fragmentos de estas ediciones antiguas con breves anotaciones y signos críticos están efectivamente atestiguados en papiros homéricos, por ejemplo, el P.Teb. 1.4 (siglo II a.C.), que conserva fragmentos del canto segundo de la Ilíada con signos críticos, o el P.Oxy 445 (siglos II-III d.C.), que tiene signos críticos y anotaciones en los márgenes del canto sexto de la Ilíada.

La principal innovación de Aristarco fue escribir comentarios para acompañar su edición: por primera vez, un erudito podía discutir sus elecciones y explicarlas; y también podía criticar a sus predecesores. El vínculo entre edición y comentario fueron los signos críticos.

Los signos críticos (sēmeia) consisten en signos de diferentes formas y diferentes significados, que fueron escritos al lado de un verso al que el filólogo tenía alguna observación que hacer. No obstante, la observación no estaba escrita en el mismo rollo que contenía el texto literario, sino en otro que contenía el comentario. Por lo tanto, los signos críticos fueron el vínculo entre la edición (ekdosis) y el comentario (hypomnèma), ya que alertaban al lector de la edición acerca de que un verso tenía un interés especial, que se trataba en el comentario adjunto. El lector podría encontrar fácilmente la nota del erudito en el comentario ya que esto había sido ordenado por lemas (representados por los versos comentados según el orden en que aparecen en la Ilíada).

En la erudición homérica, el primer signo crítico que conocemos fue inventado por Zenódoto de Éfeso. Se trata del obelos ('espetón' en griego) que era una línea corta (-) colocada al lado de un verso que se consideraba espurio. El obelos es, por lo tanto, el signo de la athetēsis, que entonces consistía en marcar un verso como espurio sin eliminarlo del texto. Aristófanes de Bizancio añadió el asteriskos (*) para indicar un verso repetido en otro lugar. Finalmente, 
Aristarco agregó la diplē (>), que tenía un uso muy genérico y amplio, ya que la agregaba a versos notables por diversas razones (lenguaje, contenido, mito, estilo, etc.). La diplè periestigmenè (> :) fue utilizada por Aristarco para marcar esos pasajes donde argumentó contra Zenódoto, quien, como dijimos, era el principal blanco de su polémica. ${ }^{16}$ Como vimos, Aristónico escribió un tratado para explicar el significado de los signos críticos de Aristarco sobre la base del comentario de este, y esta es la base de los escolios que son atribuidos a Aristónico. Los principales signos críticos utilizados por Aristarco (obelos, diple, diplē periestigmene $\bar{e}$ asteriskos) se conservan en algunos papiros y manuscritos medievales de Homero, y en particular en el Venetus $A .{ }^{17}$

\section{Aristarco sobre Homero: suposiciones}

Aristarco nunca escribió un tratado donde explicara sus principios y metodología. La única evidencia que tenemos son aquellos de sus fragmentos que tratan con preguntas específicas en los poemas homéricos. En particular, los fragmentos de Aristarco en los escolios a la Ilíada que recogí y estudié son más de cuatro mil. Es fascinante leerlos, ya que estos fragmentos muestran una metodología y consistencia muy claras, y esto es lo que me llamó la atención al principio de mi estudio. Lo que presento aquí es el resultado de mi análisis. $^{18}$

Para explicar la metodología de Aristarco, es útil distinguir entre sus suposiciones y sus principios metodológicos. Las suposiciones, en particular, son una especie de 'postulados' que Aristarco debe admitir para comenzar su trabajo sobre Homero.

La primera suposición es que Homero es un poeta impecable y sin defectos. En los fragmentos que tenemos, Aristarco nunca dice que Homero es el mejor poeta de todos los tiempos, pero esta suposición es la base de toda su obra. Por cierto, este fue un principio bastante común en la Antigüedad y también fue teorizado por Aristóteles, quien en la Poética describe claramente a Homero como el maestro de la poesía épica y como el modelo de los sucesivos géneros de la tragedia (con la Ilíada y la Odisea) y la comedia (con el Margites) (Poet. 1448b24-1449a2). Sin duda, Aristarco sigue a Aristóteles en su evaluación de la poesía homérica y en su suposición de la excelencia de Homero. La consecuencia de esta suposición es que, si hay un error en el poema, tiene que discutirlo y arreglarlo.

La segunda suposición es que Homero es un poeta autoconsistente. Solo asumiendo que Homero no se contradice nunca un estudioso puede tratar de poner orden en una tradición desordenada, como la que enfrentaban Aristarco y sus colegas. La consecuencia de esta suposición es que se puede usar un pasaje de Homero como testimonio para explicar y corregir otro pasaje de Homero. Este importante principio se resume en el famoso lema 'explicar a Homero con Homero'. Este no es un lema de Aristarco, sino de Porfirio. ${ }^{19}$ Sin embargo, este principio emerge por todas partes en la práctica filológica de Aristarco, como lo atestiguan los escolios y como veremos un poco más adelante al examinar algunos ejemplos de ello.

La tercera suposición es que Homero escribió tanto la Ilíada como la Odisea. Esta era una suposición porque la autoría de los dos poemas ya se había debatido en la antigüedad. De hecho, hubo un grupo de eruditos quienes negaron que
16. Sobre los signos críticos de Aristarcos, cfr. Schironi (2012; 2017; 2018: 49-62)

17. Sobre los signos críticos en papiros, cfr. McNamee (1992).
18. Para un estudio más profundo, cfr. Schironi (2018). Todos los escolios discutidos en este artículo se derivan de Aristónico, quien generalmente es considerado el testigo más fidedigno de los fragmentos de Aristarco, incluso si Aristarco no es citado expresamente en esos escolios.
19. Porfirio lo usa para definir su propia actitud de acercarse a Homero

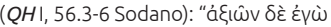

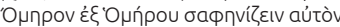

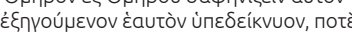

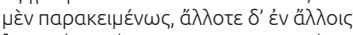
[Considerando que es correcto explicar a Homero con Homero, he demostrado que Homero se interpreta a sí mismo a veces en pasajes que están cerca, a veces en otros pasajes [más remotos]. Sobre el origen de esta máxima, cfr. Pfeiffer (1968:226-227); Wilson (1971); Lee (1975); Wilson (1976); Schäublin (1977); sobre este principio dentro del trabajo de Aristarco, ver Porter (1992:70-84). Nünlist (2015); Schironi (2018:passim). 
20. Sobre los Chorizontes, cfr. Kohl (1917); Schironi (2018:623-639).

21. Como Nietzsche afirmó en el Prólogo de l'Aurora (1881): "No en vano he sido filólogo, y tal vez lo siga siendo. La palabra 'filólogo' designa a quien domina tanto el arte de leer con lentitud que acaba escribiendo también con lentitud".

22. Cfr. Arend (1933:9297); Armstrong (1958)

23. P.Hibeh 19 (са. 285-250 a.C.) tiene un orden similar: la lanza (v. 338), seguida del escudo (v. 339a), las grebas

(v. 339b) y la espada (v. 339c); cfr. Bolling (1925:81-84); West (1967:44 y 54-55). Sobre el texto de Zenódoto en este pasaje, cfr. Nickau (1977:173-176).
Homero hubiera compuesto ambos poemas. En los escolios estos eruditos son llamados Chōrizontes (Separatistas).$^{20}$ Sin embargo, Aristarco estaba convencido de lo contrario. Esto podría ser porque esta era la opinión general; o tal vez Aristarco se convenció de que los dos poemas fueron escritos por el mismo autor porque encontró muchas similitudes entre ambos. La ventaja de esta suposición es que el filólogo tiene más evidencia a su disposición: dos poemas en lugar de uno para trabajar sobre Homero. La consecuencia es que se puede usar un pasaje de la Ilíada para explicar y corregir otro pasaje en la Odisea y viceversa.

\section{Principios de Aristarco}

Si estas son las suposiciones detrás del trabajo de Aristarco, en sus fragmentos surge también la idea de una metodología estricta, donde hay principios y reglas que un buen filólogo necesita seguir constantemente para que su trabajo sea válido.

El primer principio es que una lectura atenta del texto es imprescindible. Esto significa que antes de cambiar el texto o atetizar un verso, el filólogo debería leer y volver a leer el pasaje en cuestión porque las cosas que a primera vista parecen problemáticas podrían no serlo después de una lectura atenta. Este principio es muy interesante porque anticipa la famosa afirmación de Nietzsche de que la filología es el arte de leer lentamente. ${ }^{21}$

Este es un principio que Aristarco utiliza con frecuencia contra Zenódoto, que es un lector descuidado según Aristarco y, por lo tanto, un filólogo incompetente. Encontramos un ejemplo en un pasaje que describe una escena de armamento. La poesía homérica es poesía oral y, por lo tanto, se caracteriza por escenas que se repiten de manera casi idéntica textualmente cuando se describe la misma acción. Ejemplo de ello son las escenas de armamento de los héroes, donde se sucede siempre el mismo orden: grebas, coraza, espada, escudo, casco y lanza. ${ }^{22} \mathrm{El}$ armamento de Paris en el canto III de la Ilíada presentaba un problema. El texto de Aristarco tenía el mismo orden que el nuestro; pues en ambos Paris se pone la armadura en este orden:

» Grebas (vv. 330-331)

»Coraza (vv. 332-333)

"Espada (vv. 334-335)

Escudo (v. 335)

»Casco (vv. 336-337)

»Lanza (v. 338)

No obstante, el texto de Zenódoto era diferente. En el escolio a estos versos (Sch. Il. 3.334-5a) Aristarco dice que Zenódoto atetizó dos versos, el que mencionaba la espada (v. 334) y el otro con el escudo (v. 335), y luego añadió un verso adicional (v. 338a) con el escudo al final. No sabemos por qué Zenódoto cambió el texto -quizás tenía un manuscrito con este orden. ${ }^{23}$ Sin embargo, si lo cambió voluntariamente, podría haber sido porque para Zenódoto era difícil ver cómo un héroe podía agarrar el escudo y luego tener las manos libres para tomar el casco y la lanza. Además, en el texto de Zenódoto no había espada, probablemente porque en la pelea posterior con Menelao Paris no la usa. De nuevo, esta es una posible reconstrucción, pero no tenemos la explicación de Zenódoto. Sin embargo, así es como Aristarco entendió el texto de Zenódoto y esto está claro a partir de su 'respuesta' a él. 
El primer punto de Aristarco es que el casco y la lanza se pueden agarrar después del escudo porque el escudo se sujeta a través de correas, por lo tanto, por el torso de los héroes y no por las manos. Hay muchos escolios donde Aristarco comenta que los escudos tienen correas-por ejemplo, estos dos escolios sobre el armamento de Agamenón, uno de los cuales se refiere específicamente a la lectura de Zenódoto en el canto III:

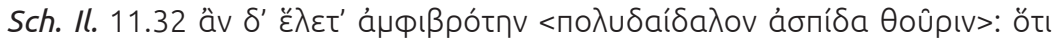

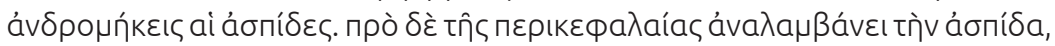

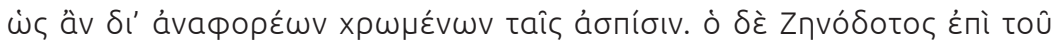

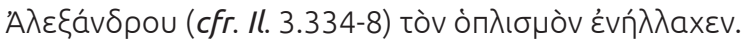

'Y tomó su escudo fuerte y elaborado con arte, que cubría a un hombre de ambos lados': porque los escudos son tan altos como un hombre. Él toma el escudo antes del casco, porque [los héroes] llevaban los escudos a través de correas. Zenódoto cambió el armamento en el caso de Paris (cfr. Il. 3.334-8)

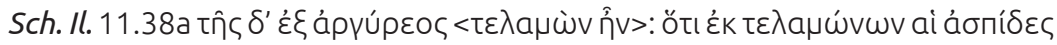
ก๊ртпทто (cfr. Sch. Il. 2.388a; 5.796; 12.401)

'Su correa era de plata': porque los escudos colgaban por correas.

El segundo punto de Aristarco es que Paris también tiene una espada y esto está claro por un verso que sigue al armamento de Paris y describe el armamento de Menelao muy rápidamente: 'Y de la misma manera se armó Menelao':

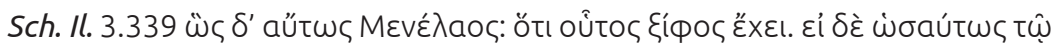

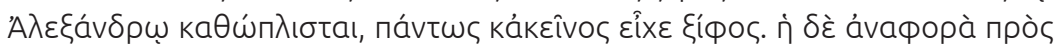

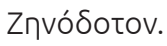

'Y de la misma manera [se armó] Menelao': porque este [i.e. Menelao] tiene una espada (cfr. v. 361). Si se ha armado de la misma manera que Alejandro, por supuesto, aquel [i.e. Alejandro] también tenía una espada. La referencia es contra Zenódoto.

Como comenta Aristarco, si el equipo de batalla es el mismo, y Menelao claramente tiene una espada en el verso 361, Paris también debe tener una espada.

¿Cuál es el objetivo de ambas observaciones de Aristarco? Podría pensarse que si tan solo Zenódoto hubiera leído este episodio y las otras escenas de armamento con más cuidado, no habría encontrado nada malo en el armamento de Paris y no habría cambiado el texto sin necesidad.

El segundo principio es que uno debe utilizar información contextual. En otras palabras, un filólogo siempre necesita referir sus explicaciones o elecciones filológicas al texto; no puede corregir el texto en términos abstractos. El contexto es primordial para decidir cualquier cosa en filología.

Un ejemplo proviene del canto II, cuando Odiseo les recuerda a los aqueos el presagio que se les apareció cuando se reunieron en Aulis: una serpiente se comió ocho pajaritos y a su madre, y Zeus la convirtió en una piedra. Homero describe a la serpiente devorando a los pajaritos mientras lloraban (Il. 2.314):

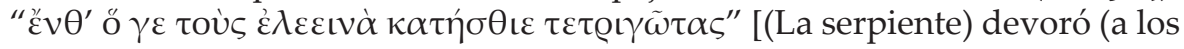
pajaritos), que estaban chillando ( $\varepsilon \varepsilon \tau \varrho \iota \gamma \tilde{\omega} \tau \alpha \varsigma)$ lastimeramente]. 
24. Sobre los Glōssographoi, cfr. Dyck (1987).

25. Cfr. Schironi (2018:247-252).
Aristarco argumenta en contra de la variante de Zenódoto, $\tau \iota \tau i ́ \zeta o v \tau \alpha \varsigma$, 'gorjeando':

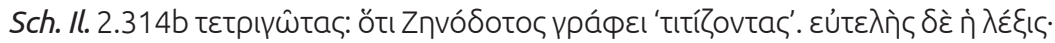

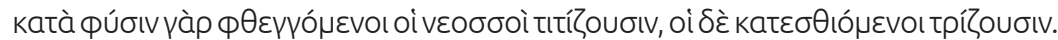

'Tetrigōtas' ['chillando']: porque Zenódoto escribe titizontas ['gorjeando'], pero la palabra es ridícula. Cuando los pájaros jóvenes cantan de acuerdo con su naturaleza, 'gorjean' [titizousi], pero los que están siendo devorados 'chillan' [trizousi].

El punto de Aristarco es que ambos verbos, $\tau \varepsilon \tau \varrho \iota \gamma \tilde{\omega} \tau \alpha \varsigma$, 'chillando', y $\tau \iota \tau i \zeta \zeta_{0} \tau \alpha \varsigma$, 'gorjeando', son muy buenos - de hecho, son excelentes verbos para los pájaros; entonces, en teoría, ambas lecturas son buenas. Sin embargo, el contexto apunta claramente a 'chillar' y no a 'gorjear', ya que aquí lo que se describe es una escena de dolor y no de alegría: los pájaros deberían llorar y no cantar. Entonces, la lectura de Zenódoto es perfecta en teoría, pero errónea dentro del contexto en el que se encuentra.

El tercer principio pide un conocimiento completo de los poemas homéricos. Con este principio, el campo es más amplio: el filólogo no solo debe prestar atención al contexto mismo del pasaje que está discutiendo, sino que también debe tener un conocimiento profundo de todo el poema. Esto es así porque a menudo es necesario comparar una palabra, episodio o mito con otros similares en otras partes del poema para encontrar la respuesta correcta.

Este principio es muy utilizado cuando se trata del vocabulario homérico, porque el significado de palabras difíciles tiene que ser deducido sobre la base de todas las ocurrencias de estas palabras en Homero. Con esta idea Aristarco polemiza con las interpretaciones de las palabras homéricas ofrecidas por los Glōssographoi. Así se les llama en los escolios a algunos exégetas homéricos anónimos. No sabemos quiénes fueron estos Glōssographoi. El nombre sugiere que fueron eruditos interesados en clarificar el significado de las palabras difíciles en Homero (glōssai). ${ }^{24}$ Para Aristarco el problema era que los Glōssographoi consideraban solamente un pasaje homérico a la vez en sus análisis, sin tomar en consideración otras apariciones de la misma palabra en Homero. ${ }^{25}$ Un ejemplo proviene del proemio de la Ilíada:

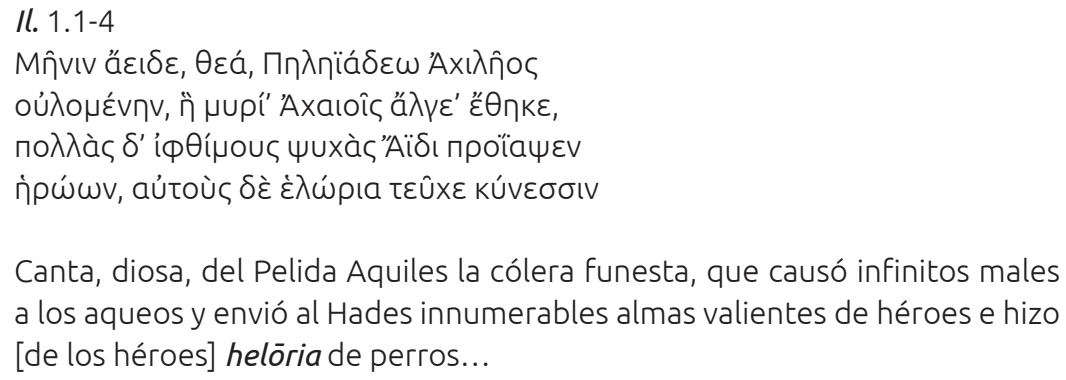

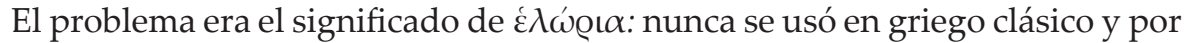
lo tanto los lectores helenísticos estaban perdidos sobre su significado exacto.

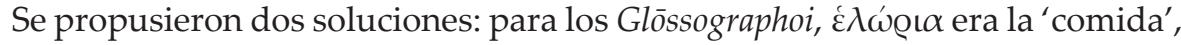
para Aristarco, la 'presa'. Claramente, en este contexto ambas soluciones funcionan, ya que los cadáveres son presa de los perros que se los comerán. Por

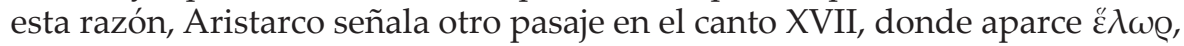
una forma singular conectada con $\varepsilon \dot{\lambda} \omega \dot{\varrho} \iota \alpha$ : 
Il. 17.150-151:

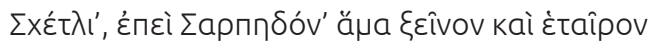

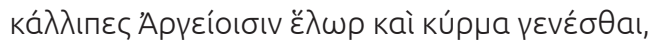

[Glauco a Héctor]: '[¿Cómo ibas tú a salvar en la turba a un guerrero menor,] cruel, si a Sarpedón, tu huésped y compañero, lo dejaste ser helōr [presa] y botín de los argivos?'

Sobre estos versos Aristarco nota:

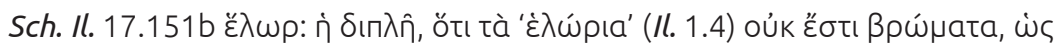

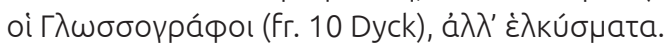

'Presa (helōr)': la diplē [está aquí] porque helōria (Il.1.4) no es 'lo que se come', como dicen los Glōssographoi, sino 'lo que se desgarra' [i.e. presa].

En este pasaje, Glauco reprende a Héctor porque dejó a Sarpedón como presa ( $\check{\lambda} \lambda \omega Q)$ de los griegos. Aquí está claro que $\varepsilon ̋ \omega \varrho$ solo puede significar 'presa' porque si significara 'comida' los griegos serían caníbales. Ahora bien, dado que Homero es autoconsistente, usa la misma palabra en todos sus poemas con el mismo significado; por lo tanto, Aristarco concluye, los Glōssographoi estaban equivocados. ${ }^{26}$

El último principio considera los poemas homéricos como un microcosmos autosuficiente. Esto significa también que Aristarco siempre hace una clara distinción entre Homero y el resto de los poetas que vienen más tarde (a quienes llama Neōteroi), porque estos últimos son diferentes en todo: en el lenguaje, en el estilo poético, en los mitos, etc. La consecuencia es que, como regla general, el filólogo no puede usar otros poetas para explicar o corregir a Homero. Solo Homero es una buena evidencia para sí mismo. ${ }^{27}$

Un ejemplo de la diferencia entre Homero y los poetas posteriores se refiere al mito de Heracles. En poetas posteriores, por ejemplo Hesíodo (Th. 950-955) o Píndaro (Nem. 1.69-72), después de la muerte Heracles se vuelve inmortal y se casa con Hebe. Aristarco observa que este no es un mito conocido por Homero porque Heracles en Homero es claramente mortal, como lo demuestra Aquiles que en el canto XVIII de la Ilíada, para consolar a su madre de su muerte prematura, dice que ni siquiera Heracles pudo escapar a la muerte (v. 117: "oú $\delta \dot{\varepsilon}$

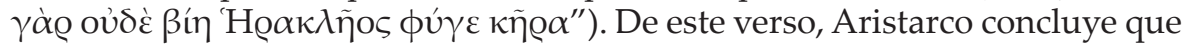

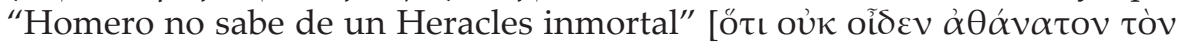

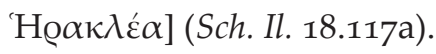

En cuanto a que Hebe es la esposa de Heracles, ella no puede estar casada con Heracles en Homero porque en la Ilíada Hebe realiza tareas típicas de mujeres solteras: verter vino en la mesa de los dioses y bañar a los dioses masculinos como Ares, lo cual sería muy inadecuado si estuviera casada con Heracles:

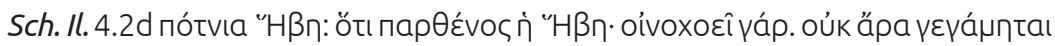

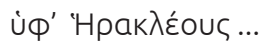

'Augusta Hebe': porque Hebe es soltera, ya que ella vierte vino. Entonces ella no está casada con Heracles ...

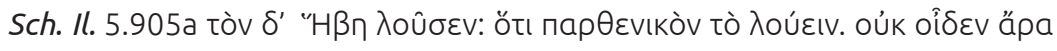

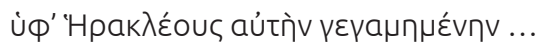

26. Cfr. Lehrs (1882:103); Dyck (1987:123 y 140).

27. Sin embargo, hay excepciones: cuando Homero no ofrece evidencia interna para aclarar un problema, Aristarco usa poetas posteriores; cfr. Schironi (2018:346-348, 656-657, 695-697) 
28. Que el baño de alguien era una tarea para jóvenes vírgenes y no mujeres casadas está demostrado, según Aristarco, por Od. 3.464-465, cuando Policasta, co (Sch. Od. 3.464b): “ötı ùnò nap $\theta \varepsilon ́ v \omega v$

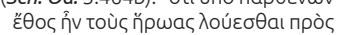

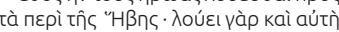

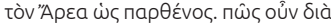

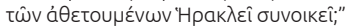
porque era costumbre que los héroes forque era costumbre que fueran bañados por mujeres solteras. Con referencia a la cuestión de Hebe, porque ella misma baña a Ares, porque ella es soltera. Por lo tanto, ¿cómo puede estar viviendo con Heracles en los versos que son atetizados?]. En cuanto a servir vino, Aristarco pudo observar que en Homero esta es una tarea típica de los hombres jóvenes; por ejemplo, en $I l$. 20.234 se dice que el joven Ganimedes fue tomado por los dioses para servir como copero para Zeus (cfr. Sch. Il.

20.234a). Cfr. Kohl (1917:46-51 fr.*13); Severyns (1928:130-132, 175-177).

29. Cfr. Schironi (2009).
'Y Hebe lo bañó': porque bañar a alguien es una actividad para mujeres solteras. Homero no sabe que Hebe está casada con Heracles... 28

\section{6. ¿Demasiada consistencia? Algunos problemas con el método 'científico' de Aristarco}

Ahora bien, todos estos ejemplos muestran que Aristarco es un filólogo extremadamente coherente y preciso. Él usa un método que, hasta cierto punto, puede definirse como 'científico'. Creo que esta es una gran contribución al desarrollo de la filología como una disciplina que puede pretender ofrecer algunos resultados válidos. Pero también hay algunos problemas con esta actitud científica, como voy a explicar a continuación. Lo haré volviendo a las tres suposiciones iniciales y mostraré lo que puede suceder cuando se aplican a Homero.

La primera suposición es que Homero es un poeta perfecto. En esto, como he dicho, Aristarco parece seguir el juicio de Aristóteles sobre Homero como el mejor poeta épico. En particular, para Aristóteles, un buen poeta siempre debe crear personajes que se adapten a su caracterización y contexto (Poet. 1454a1628). Del mismo modo, las palabras de los personajes deben adaptarse a los personajes mismos que las hablan y a la situación en la que se hablan (Poet. 1454a33-36; Rhet. 1408a25-32). Entonces, Aristarco atetiza los versos que no son apropiados para personajes o situaciones específicas. En esto, sigue completamente las reglas de Aristóteles de la buena poesía. ${ }^{29}$

Un ejemplo divertido proviene del episodio de la seducción de Zeus por Hera en el canto XIV. Para distraer a Zeus y así poder ayudar a los griegos, Hera lo seduce. En el punto culminante de la escena de la seducción, cuando Zeus está completamente cautivado por los encantos de su esposa, él le dice a Hera que nunca ha sentido tal deseo por una mujer o diosa (Il. 14.317-327) enumerando a todas sus amantes (Dia, Danae, Europa, Semele, Alcmena, Demeter, y Leto). Está claro que Zeus hace lo que enfurecería a cualquier mujer. Y Aristarco parece haber tenido la misma opinión:

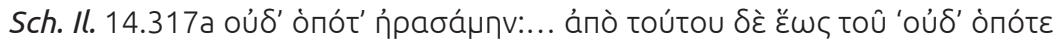

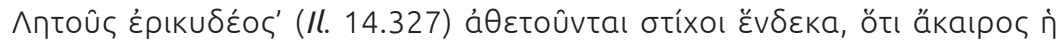

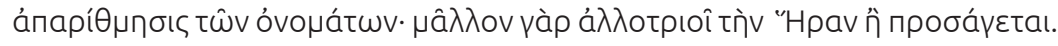

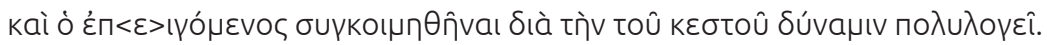

'Ni siquiera cuando me enamoré': ... Desde aquí hasta 'ni siquiera cuando [me
enamoré] de la gloriosa Leto' (Il. 14.327) once versos son atetizados porque
contar los nombres [de sus amantes] está fuera de lugar. Porque hace que Hera
sea hostil en lugar de atraerla hacia sí mismo. Y para alguien que tiene que
acostarse con ella gracias al poder de la faja [de Afrodita], él habla demasiado.

La solución de Aristarco es obvia: ¡la atetesis de los versos incriminados! No podemos más que estar de acuerdo con él desde un punto de vista puramente psicológico. Pero esto no tiene nada que ver con un trabajo filológico sobre Homero. Porque (y debemos notar esto) Aristarco no tiene ninguna evidencia externa de que esos versos no sean originales. Esta es simplemente su propia idea basada en su suposición de que Homero es realmente el mejor poeta de acuerdo con los dictados de Aristóteles y que entonces él no puede representar a Zeus hablándole de esta manera a su esposa. 
La segunda suposición es que Homero es autoconsistente. La consecuencia es que cualquier inconsistencia en el poema debe ser eliminada o solucionada. El problema con este procedimiento es que hay muchas inconsistencias en poemas orales como la Ilíada. Un ejemplo son los héroes 'resucitados'. Lo que ocurre es que en Homero los personajes menores mueren y luego reaparecen vivos algunos cantos después. Esto sucede porque el poeta oral usa muchos personajes menores y a veces se olvida de que uno ya murió y lo usa de nuevo. La solución de Aristarco es que estos personajes resucitados no son el mismo personaje de ninguna manera; simplemente tienen el mismo nombre (cfr. Sch. Il. 2.517c; 15.515a).

Uno de estos héroes resucitados es particularmente interesante para comprender los defectos en el método filológico de Aristarco. Pilémenes es el comandante de los paflagones; Menelao lo mata en el canto V (vv.576-579) pero luego lo encontramos vivo otra vez cuando matan, por su parte, a su hijo Harpalión. Así es como Homero describe la muerte de Harpalión:

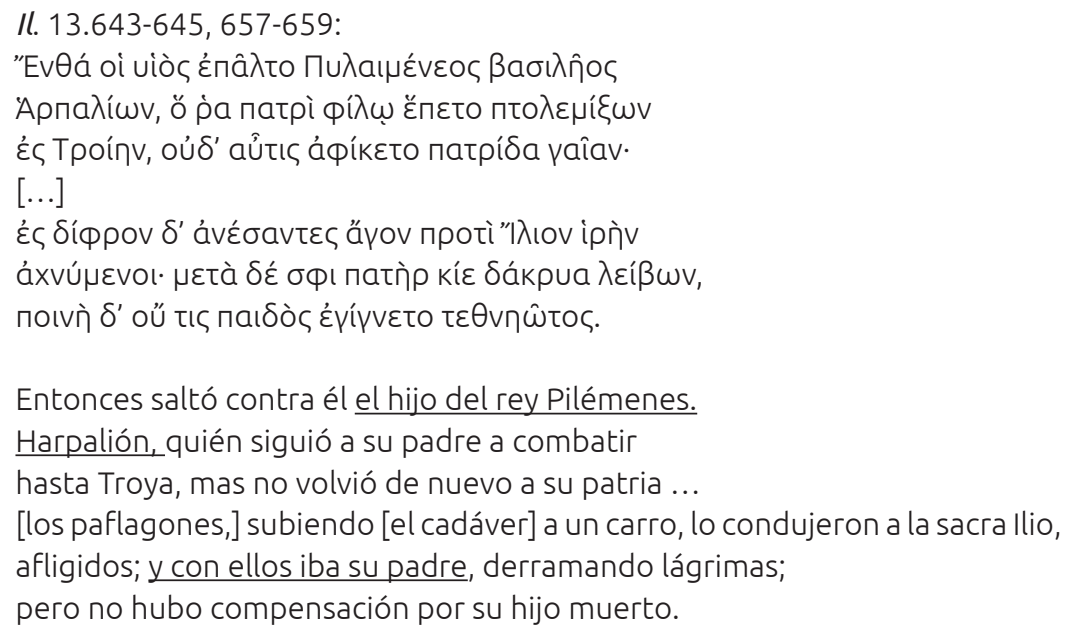

La solución de Aristarco es la atetesis de los dos últimos versos ('afligidos; y con ellos iba su padre, derramando lágrimas; pero no hubo compensación por su hijo muerto') bajo la justificación de que están interpolados:

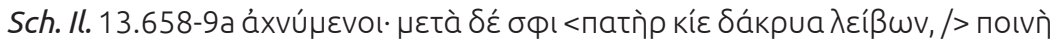

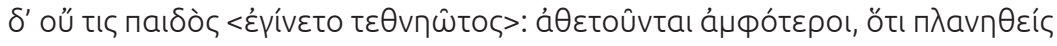

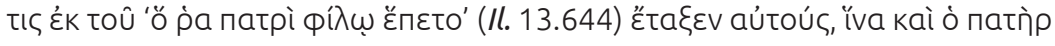

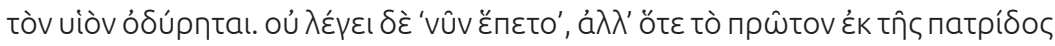

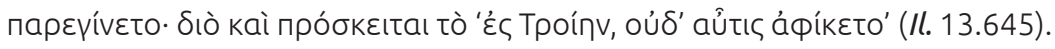

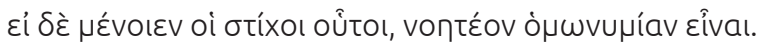

'Afligidos; y con ellos iba su padre, derramando lágrimas; pero no hubo compensación por su hijo muerto': los dos versos son atetizados, porque alguien confundido por '[Harpalión,] quien siguió a su padre' (Il. 13.644) los añadió, para que el padre también pudiera llorar al hijo. Pero él no dice: '[quien] luego siguió', sino cuando venía de su país y lo acompañó: por lo tanto, también se agrega el verso 'hasta Troya, mas no volvió de nuevo [a su patria]' (l. 645). Pero si estos dos versos permanecen, debemos considerarlo como un caso de homonimia.

Según Aristarco, un interpolador malinterpretó la cláusula relativa en Il.13.644645: 'Harpalión, quien siguió a su padre a combatir hasta Troya, mas no volvió 
30. El 'problema de Pilémenes' sigue siendo objeto de los debates modernos; cfr. Bolling (1944:134-135); Tsagarakis (1976); Janko (1994:126).

31. Cfr. también Sch. Il. $4.2 \mathrm{~d}$ :

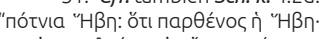

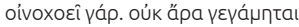

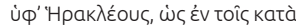
tìv Nćkulav ñ日 1.602-604) ['Augusta Hebe': porque Hebe es soltera, ya que ella vierte vino. Entonces ella no está casada con Heracles como en los versos atetizados en la Nekyia] y Sch. Il. 5.905: "tòv $\delta^{\prime}$

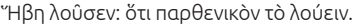

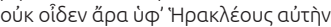

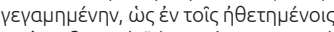

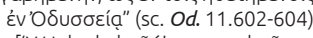
... ['Y Hebe lo bañó': porque bañar a alguien es una actividad para mujeres solteras. Homero no sabe que Hebe está casada con Heracles como en los versos atetizados en la Odisea]. de nuevo a su patria'. La frase se refiere claramente al comienzo de la guerra de Troya, diez años antes; pero, según Aristarco, el interpolador consideró que la cláusula relativa se refería a esa acción específica: si Harpalión había seguido a su padre ese día, obviamente su padre tenía que estar presente para llorar a su hijo cuando a éste lo mataron. Todo esto es ingenioso, pero una vez más Aristarco no tiene ninguna prueba de que estos versos estén interpolados. Por ejemplo, no dice que encontró manuscritos sin esos versos. Básicamente asume que estos versos están interpolados para salvar a Homero de la inconsistencia. ${ }^{30}$ De hecho, el mismo Aristarco parece no estar tan seguro de su solución y, por lo tanto, propone una opción alternativa: sugiere que si uno quiere mantener los versos (que entonces 'no' están 'claramente' interpolados),

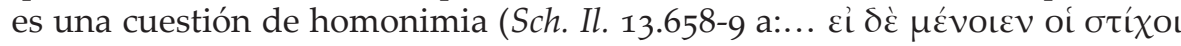

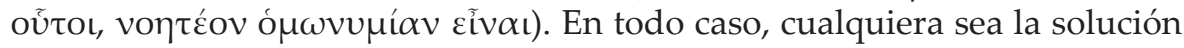
que se elija, Homero se salva de ser inconsistente.

La última suposición es que Homero había escrito ambos poemas. Por lo tanto, dado que Homero es también un autor consistente, no debería haber ninguna inconsistencia entre ellos y, si la hay, tiene que ser eliminada o resuelta.

El mito de Heracles que hemos analizado anteriormente ofrece un caso interesante. Como vimos, para Aristarco Homero no conoce el mito de un Heracles inmortal casado con Hebe. El problema es que en la Odisea, en el canto XI, cuando Odiseo visita el Inframundo, Heracles es descrito como inmortal y casado con Hebe. ¿Y qué hace Aristarco? Obviamente, rechaza los versos de la Odisea y afirma que son neotéricos, es decir, más tardíos y, por lo tanto, una interpolación:

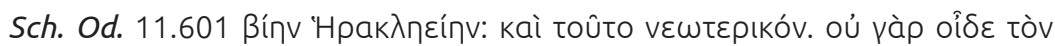

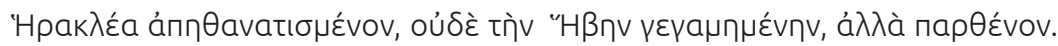

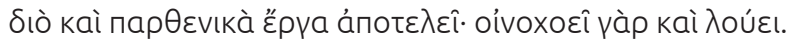

'La fuerza de Heracles': esto también es neotérico. [Homero] no sabe de la deificación de Heracles ni del matrimonio de Hebe, pero [él sabe que ella] es soltera. Por lo tanto, ella también realiza tareas típicas de mujeres solteras: vierte vino y baña [a otros dioses]. ${ }^{31}$

Sin embargo, lo que Aristarco está haciendo aquí es eliminar inconsistencias entre los dos poemas para que puedan haber sido escritos por el mismo poeta que es además consistente. Pero esta es claramente una interpretación forzada y una manipulación del texto.

\section{Conclusiones}

Para concluir, creo que Aristarco es de hecho el fundador de la filología porque establece una disciplina con una metodología sólida, basada en suposiciones y reglas y principios estrictos, que sigue consistentemente. Por añadidura, y más importante aún, su trabajo siempre se basa en el texto mismo, lo cual es una regla de oro de la filología o, al menos, debería serlo.

Estas innovaciones fueron posibles también porque Aristarco 'inventó' el género del 'comentario filológico' que se convierte en un lugar donde el filólogo puede discutir sus elecciones, hacer sus propuestas y atacar a sus predecesores. El comentario entonces permite al filólogo pensar más profundamente sobre su método y cómo aplicarlo de la mejor manera. 
Sin duda, estos pasos fundamentales para el desarrollo de la filología son el resultado del enfoque innovador de Aristarco para trabajar en un texto literario; en esto, ciertamente se merece el título de 'padre fundador' de la filología. Pero el problema fundamental de su método científico y consistente es que Aristarco lo aplica a algo que es inconsistente por naturaleza. En otras palabras, Aristarco 'fuerza' a Homero a encajarse en sus suposiciones, de modo que básicamente crea a su propio Homero. El Homero de Aristarco (y solo 'su' Homero) es un poeta autoconsistente e impecable de acuerdo con las teorías poéticas de Aristóteles, y el autor único de la Ilíada y de la Odisea. Al final, el Homero de Aristarco es en parte la criatura de Aristarco.

Gracias al hecho de que Aristarco hizo todas sus elecciones editoriales en su comentario y no las insertó directamente en el texto homérico, todavía podemos ver el Homero 'original' (aunque cortado y 'seleccionado' en términos del número del verso) y aún así apreciar lo que Aristarco quería que fuese su Homero. Es una historia fascinante, que también debería hacernos reflexionar sobre aquello de lo que realmente se trata la filología y sobre la común suposición de que la filología se trata de una verdadera y 'científica' reconstrucción de un texto. 


\section{Q Bibliografía}

》 Apthorp, M. J. (1980). The Manuscript Evidence for Interpolation in Homer. Heidelberg: Carl Winter.

»Arend, W. (1933). Die typischen Scenen bei Homer. Berlin: Weidmann

»Armstrong, J. I. (1958). "The Arming Motif in the Iliad", AJPh 79, 337-354.

» Bagnall, R. S. (2002). "Alexandria: Library of Dreams", PAPHS 146, 348-362.

» Bolling, G. M. (1925). The External Evidence for Interpolation in Homer. Oxford: Oxford University Press.

» Bolling, G. M. (1944). The Athetized Lines of the Iliad. Baltimore: Waverly Press.

» Boys-Stones, G. R. (ed.) (2003). Metaphor, Allegory, and the Classical Tradition: Ancient Thought and Modern Revisions. Oxford: Oxford University Press.

" Buffière F., (1956). Les mythes d'Homère et la pensée grecque. Paris: Les Belles Lettres.

» Collart, P. (1933). "Les papyrus de l'Iliade (2e article)", RPh 7, 33-61.

”Dyck, A. R. (1987). "The Glossographoi", HSPh 91, 119-160.

»Eichgrün, E. (1961). Kallimachos und Apollonios Rhodios. Diss. Berlin: E. Reuter.

» Erbse, H. (1959). "Über Aristarchs Iliasausgaben”, Hermes 87, 275-303.

»Erbse, H. (1969). Scholia Graeca in Homeri Iliadem (scholia vetera), vol. I. Berlin: W. de Gruyter.

» Fraser, P.M. (1972). Ptolemaic Alexandria. 3 vols. (I Text; II Notes; III Indexes). Oxford: The Clarendon Press.

"Haslam, M. (1997). "Homeric Papyri and Transmission of the Text". En: Morris, I.; Powell, B. (eds.). A New Companion to Homer. Leiden; New York; Köln: Brill, 55-100.

" Janko, R. (1994). The Iliad: a Commentary. Volume IV: Books 13-16. Cambridge: Cambridge University Press.

"Jensen, M. S. (1980). The Homeric Question and the Oral-Formulaic Theory, Copenhagen: Museum Tusculum Press.

» Kohl, J. W. (1917). De Chorizontibus. Darmstadt: Benderi.

» Labarbe, J. (1949). L' Homère de Platon. Liège: Faculté de Philosophie et Lettres.

" Lamberton, R. (1992). "The Neoplatonists and the Spiritualization of Homer". En: Lamberton, R.; Keaney, J. J. (eds.). Homer's Ancient Readers: the Hermeneutics of Greek Epic's Earliest Exegetes. Princeton: Princeton University Press, 115-133.

» Lee, G. (1975). "An Aristarchean Maxim?", PCPhS 21, 63-64.

» Lehrs, K. (1882). De Aristarchi studiis Homericis. Leipzig: Teubner.

"Long, A. A. (1992). "Stoic Readings of Homer". En: Lamberton, R.; Keaney, J. J. (eds.). Homer's Ancient Readers: the Hermeneutics of Greek Epic's Earliest Exegetes. Princeton: Princeton University Press, 41-66.

» Lührs, D. (1992). Untersuchungen zu den Athetesen Aristarchs in der Ilias und zu ihrer Behandlung im Corpus der exegetischen Scholien. Hildesheim; Zürich; New York: Olms.

» McNamee, K. (1992). Sigla and Select Marginalia in Greek Literary Papyri. Papyrologica 
Bruxellensia 26. Bruxelles: Fondation Égyptologique Reine Élisabeth.

» Nagy, G. (1996). Poetry as Performance: Homer and Beyond. Cambridge: Cambridge University Press.

"Nagy, G. (2009). Homer the Classic. Hellenic Studies 36. Washington: Center for Hellenic Studies.

» Nickau, K. (1977). Untersuchungen zur textkritischen Methode des Zenodotos von Ephesos. Berlin; New York: de Gruyter.

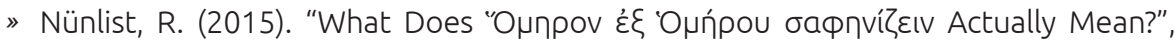
Hermes 143, 385-403.

»Pasquali, G. (1962). Storia della tradizione e critica del testo. Firenze: Le Monnier.

» Pfeiffer, R. (1968). History of Classical Scholarship. Vol. 1: From the Beginnings to the End of the Hellenistic Age. Oxford: Oxford University Press.

" Pontani, F. (2005). Sguardi su Ulisse. La tradizione esegetica greca all'Odissea, Sussidi eruditi 63. Rome: Edizione de Storia e Letteratura.

"Porter, J. I. (1992). "Hermeneutic Lines and Circles: Aristarchus and Crates on the Exegesis of Homer". En: Lamberton R.; Keaney, J. J. (eds.). Homer's Ancient Readers: the Hermeneutics of Greek Epic's Earliest Exegetes. Princeton: Princeton University Press, 67-114.

» Russo, L. (2004). The Forgotten Revolution. How Science Was Born in 300 BC and Why It Had to Be Reborn. With the collaboration of the translator, S. Levy. Berlin; Heidelberg: Springer.

»Schäublin, Ch. (1977). "Homerum ex Homero", MH34, 221-227.

"Schironi, F. (2009). "Theory into Practice: Aristotelian Principles in Aristarchean Philology", CPh 104, 279-316.

» Schironi, F. (2012). "The Ambiguity of Signs: Critical $\Sigma$ пneia from Zenodotus to Origen". En: Niehoff, M. R. (ed.). Homer and the Bible in the Eyes of Ancient Interpreters. Jerusalem Studies in Religion and Culture 16.Leiden; Boston: Brill, 87-112.

» Schironi, F. (2017). "Tautologies and Transpositions: Aristarchus' Less Known Critical Signs", GRBS 57, 607-630.

» Schironi, F. (2018). The Best of the Grammarians: Aristarchus of Samothrace on the lliad. Ann Arbor: University of Michigan Press.

" Schironi, F. (2019). "Enlightened King or Pragmatic Rulers? Ptolemaic Patronage of Scholarship and Sciences in Context". En: Bosman, Ph. (ed.). Intellectual and Empire in Greco-Roman Antiquity. New York; London: Routledge, 1-29.

» Severyns, A. (1928). Le cycle épique dans l'école d'Aristarqu. Liege; Paris: VaillantCarmanne; E. Champion.

» Struck, P. T. (2004). Birth of the Symbol: Ancient Readers at the Limits of Their Texts. Princeton: Princeton University Press.

" Tsagarakis, O. (1976). "'Pylaimenes' Tod und Auferstehung: Ein Widerspruch in der Ilias?"', Hermes 104, 1-12.

» van Groningen, B. A. (1963). Traité d'histoire et de critique des textes grecs. Amsterdam: N. V. Noord-Hollandsche Uitgevers Maatschappij.

»Wehrli, F. (1928). Zur Geschichte der allegorischen Deutung Homers im Altertum. Leipzig: Teubner. 
» West, M. L. (2001). Studies in the Text and Transmission of the lliad. München; Leipzig: M. L. West.

»West, S. (1967). The Ptolemaic Papyri of Homer. Papyrologica Coloniensia 3. Köln; Opladen: Westdeuscher.

"Wilson, N. G. (1971). "An Aristarchean Maxim", CR21, 172.

»Wilson, N. G. (1976). "Aristarchus or a Sophist?", PCPhS 22, 123. 